\title{
Qualitative smell/taste disorders as sequelae of acute COVID-19
}

\author{
Tommaso Ercoli $^{1}$ - Carla Masala ${ }^{2} \cdot$ Ilenia Pinna ${ }^{2} \cdot$ Gianni Orofino $^{3} \cdot$ Paolo Solla $^{4} \cdot$ Lorenzo Rocchi $^{1,3}$. \\ Giovanni Defazio ${ }^{1,3}$
}

Received: 14 June 2021 / Accepted: 10 September 2021 / Published online: 23 September 2021

(C) The Author(s) 2021

\begin{abstract}
Background Qualitative smell/taste disorders (such as phantosmia, parosmia, phantogeusia, and parageusia) have not yet been fully characterized in patients who had COVID-19, whereas quantitative disturbances (i.e., reduction/loss of smell/ taste) have been widely investigated.

Objective To simultaneously assess the presence of both quantitative and qualitative smell/taste dysfunctions in patients who suffered from COVID-19.

Methods We enrolled 17 consecutive patients who suffered from COVID-19 over the last 6 months and 21 healthy controls, matched for sex and age. After a negative nasopharyngeal swab, the Sniffin' Sticks Test and the Taste Strips were used to assess olfactory and taste function, respectively. At the same time, the presence of phantosmia, parosmia, phantogeusia, and parageusia was investigated with a standardized questionnaire.

Results Qualitative disturbances of smell and/or taste were found in 6/17 (35.3\%) patients. Phantosmia was reported in 2/17 $(11.8 \%)$ patients and parosmia in 4/17 (23.5\%). There were no significant differences in smell test scores between patients who reported phantosmia and/or parosmia and patients who did not. Phantogeusia was described in 3/17 (17.6\%) patients, and parageusia was identified in 4/17 (23.5\%) patients. All tested patients were normogeusic.

Conclusion Around one-third of patients who recover from COVID-19 may have persistent qualitative dysfunction in smell/ taste domains. Detection of phantogeusia in long-term COVID-19 patients represents a further novel finding. Further investigation is needed to better characterize the pathophysiology of phantosmia, parosmia, phantogeusia, and parageusia in patients who had COVID-19.
\end{abstract}

Keywords COVID-19 $\cdot$ Phantogeusia $\cdot$ Olfactory hallucination $\cdot$ Smell $\cdot$ Taste

\section{Introduction}

Olfactory and taste dysfunctions are among the most prevalent symptoms of the acute phase of the coronavirus disease of 2019 (COVID-19) [1, 2]. Their presentation is variable, including total or partial loss of smell (anosmia/hyposmia)

Tommaso Ercoli

ercolitommaso@me.com

1 Department of Medical Sciences and Public Health, Institute of Neurology, University of Cagliari, Cagliari, Italy

2 Department of Biomedical Sciences, University of Cagliari, Monserrato, Italy

3 Institute of Neurology, Azienda Ospedaliero Universitaria di Cagliari, Cagliari, Italy

4 Department of Neurology, University of Sassari, Sassari, Italy and taste (ageusia/hypogeusia), distorted perception of smell/taste (parosmia and parageusia), and perception of an odor or a taste without any concurrent stimulus (phantosmia, also known as olfactory hallucination, and phantogeusia, also known as gustatory hallucination) [3]. Distorted/hallucinatory perceptions of smell/taste are typically highlighted during clinical interview, whereas loss of smell/taste is usually disclosed by objective tests, like the Sniffin' Sticks Test and the Taste Strips, respectively.

Although reduction/loss of smell/taste during the acute phase of the 2019 novel coronavirus SARS-CoV-2 infection and the following months has been investigated [4, 5], little is known about qualitative smell/taste symptoms [6]. As far as olfactory hallucinations are concerned, only one study evaluated phantosmia long after the acute phase of COVID19 [7]. On the other hand, parosmia and parageusia have already been described as COVID-19 sequalae, but only a 
few studies also provided objective measures of olfactory/ gustatory function.

Therefore, the pathophysiological mechanisms underlying olfactory/taste dysfunctions after COVID-19 are still debated. To expand current knowledge, in this study, we simultaneously assessed the presence of qualitative smell/ taste disturbances and objectively measured smell/taste in patients recovering from COVID-19.

\section{Methods}

Seventeen consecutive patients seen over the last 6 months at the Medical Department of the University Hospital of Cagliari $[8,9]$ participated into the study. According to the disease severity scoring of World Health Organization [10], COVID-19 manifested in severe form in $1 / 17$ patients $(5.8 \%)$ that required hospitalization, while $8 / 17$ patients $(47.1 \%)$ suffered from a moderate form (clinical evidence of pneumonia with $\mathrm{SpO} 2 \geq 90 \%$ ), and 8/17 patients (47.1\%) reported a mild symptomatology and were treated at home. Patients were examined $63.6 \pm 40.8$ days (range 8-151 days) after the negative nasopharyngeal swab. Exclusion criteria were history of head or neck trauma [11-13], cognitive impairment and psychiatric conditions interfering with study participation $[14,15]$, chronic/acute rhinosinusitis, neurological diseases involving smell/taste function [16-18], and systemic diseases related to smell/taste disorders [19].

The Sniffin' Sticks Test (Burghart Messtechnik, Wedel, Germany) and the Taste Strips (Burghart Messtechnik, Wedel, Germany) were administered to both patients and healthy controls by an examiner who did not know whether the subject complained of qualitative smell/taste disturbances. Seventeen patients were compared with twenty-one healthy controls, matched for sex (10/17 vs. 14/21 females, $p=0.74)$ and age $(35.8 \pm 17.5$ vs. $35.5 \pm 11.1, p=0.73)$. Healthy controls were from a pool of healthy subjects that had been tested by the Sniffin' Sticks Test and the Taste Strips before the pandemic (in the first semester of 2019). Full description of the methodology of smell/taste tests is provided elsewhere [20-22]. In brief, the Sniffin' Sticks Test takes into account three different parameters: odor threshold (OT), odor discrimination (OD), and odor identification
(OI). A total score (TDI, resulting from the sum of the OT, OD, and OI scores) $>30.5, \leq 30.5$, and $\leq 16.5$ indicates normosmia, hyposmia, and anosmia, respectively. Taste Strips assess four taste modalities (sweet, bitter, sour, and salty) using four concentrations for each modality. Taste Strips total score ranges from 0 to 16 , with a score $<9$ indicating hypogeusia.

After performing objective smell/taste tests, patients and controls were also asked about smoking history, as well as by ongoing and prior occurrence of phantosmia, parosmia, phantogeusia, and parageusia by a standardized interview characterized by a brief description/explanation of qualitative alterations of smell/taste [22]. No healthy control reported ongoing or prior occurrence of distorted/hallucinatory perception of smell/taste.

Statistical analysis was performed with the Stata 11.0 package (StataCorp LP, College Station, TX). Data were expressed as mean \pm standard deviation unless otherwise indicated. Differences between groups were examined by chi-square test, Fisher's exact test, or the Mann-Whitney U test as appropriate [23-25]. For all analyses, significance was set at 0.05 .

\section{Results}

Patients were examined 63.6 \pm 40.8 days (range 8-151) after the negative nasopharyngeal swab. Qualitative disturbances of smell and/or taste starting during the acute phase of the 2019 novel coronavirus SARS-CoV-2 were found in 6/17 patients (35.3\%) $99 \pm 30.1$ days after the negative swab. The remaining $11 / 17$ patients did not experience any qualitative symptoms of smell/taste either during the acute phase of COVID-19 or on examination performed $44.3 \pm 32.3$ days after the negative swab. The time elapsing between the negative swab and examination was significantly shorter in the 11 patients without qualitative smell/taste disturbances after COVID-19 $(p=0.003)$. No patients reported olfactory or gustatory disturbances before COVID-19.

Among the six patients who reported qualitative smell and/or taste disturbances, both domains were affected in three patients, the smell domain alone in two patients, and the taste domain alone in one patient (Table 1). Smell/taste
Table 1 Qualitative disturbances of smell and/or taste in six patients who had COVID-19. All patients were normogeusic according to the Taste Strip test total score

\begin{tabular}{lllllll}
\hline Patients & Phantosmia & Parosmia & Anosmia & Hyposmia & Phantogeusia & Parageusia \\
\hline n. 1 & N & Y & - & Y & Y & Y \\
n. 2 & Y & Y & - & Y & N & Y \\
n. 3 & N & Y & - & - & N & N \\
n. 4 & N & Y & - & - & N \\
n. 5 & N & N & - & - & Y & Y \\
n. 6 & Y & N & Y & - & Y & Y \\
\hline
\end{tabular}


disturbances were found in $1 / 1$ patient who had the severe form of COVID-19, in $4 / 8$ patients who suffered from the moderate form, and in $4 / 8$ patients who had the mild form ( $p=0.94)$, likewise there was no difference among smokers and ever smokers in the COVID-19 group $(p=0.62)$.

Qualitative smell disturbances were reported by five patients. Phantosmia was reported by one patient (5.8\%) who was anosmic and described olfactory hallucination as a strong and disgusting odor (e.g., burning smell); parosmia was reported by $3 / 17$ patients (17.6\%), of whom one was hyposmic and two were normosmic on the Sniffin' Sticks Test; a further hyposmic patient reported both phantosmia (defined as a slight and pleasant smell) and parosmia. All patients with parosmia described an unpleasant distorted perception of smell (e.g., smell of garbage/rotten food while eating).

Qualitative taste abnormalities were reported by four patients. Both phantogeusia and parageusia were found in $3 / 17$ patients $(17.6 \%)$ : one patient described the gustatory hallucination as a strong and disgusting taste, while the other two patients experienced a slight and pleasant flavor (e.g., sweet taste without a meal). Parageusia alone was identified in one patient (5.8\%). Three patients described parageusia as an unpleasant distorted perception of gustatory sense (e.g., fuel/iron and plastic taste while eating), while one patient described the misperception as slight and pleasant.

In comparison to controls, patients showed a significant decrease in olfactory function as assessed by the Sniffin' Sticks Test (Fig. 1) (TDI score: $34.1 \pm 3.2$ vs. $27.6 \pm 6.7, p$ $<0.001)$. The two groups were similar in terms of sex (10 women and 7 men vs. 14 women and 7 men, $p=0.51$ ), age $(35.8 \pm 17.5$ vs. $35.5 \pm 11.1, p=0.95)$, and smoking history (11 non-smokers and 6 ever smokers vs. 15 non-smokers and 7 ever smokers, $p=0.46$ ). There was no significant difference in the Sniffin' Sticks Test between the five patients who reported phantosmia and/or parosmia and the twelve patients who did not (TDI score: $25.5 \pm 7.1$ vs. $28.4 \pm 6.5, p=$ $0.43)$. According to the cut-off from the Sniffin' Sticks Test, $1 / 17(5.8 \%)$ patient was anosmic and 8/17 (47.1\%) patients were hyposmic and 8/17 (47.1\%) patients were normosmic.
Hyposmia/anosmia was found in $3 / 5$ patients who reported phantosmia/parosmia and in 6/12 patients who did not (Fisher's test, $p=1)$. Stratifying the results of the Sniffin' Sticks Test by OT, OD, and OI in the five patients who reported phantosmia/parosmia and the twelve patients who did not, no significant differences were detected between the two groups (OT score: $2.6 \pm 2.1$ vs. $4.8 \pm 4.7, p=0.32$; OD score: $11.2 \pm 3.9$ vs. $10.6 \pm 2.8, p=0.71$; OI score: 11.8 \pm 2.3 vs. $13 \pm 1.5, p=0.22$ ). Comparing the three patients who had parageusia/phantogesia associated to hyposmia/ anosmia to the three patients who were normosmic yielded non-significant differences in $\mathrm{OD}(9 \pm 3.5$ vs. $13.7 \pm 1.5, p$ $=0.1)$ and $\mathrm{OI}(10.7 \pm 2.3$ vs. $13.7 \pm 0.6, p=0.09)$.

Although the total score from Taste Strip test was slightly but significantly lower in COVID-19 patients than in controls (Fig. 1), Taste Strip values from COVID-19 patients were all in the range of normal taste.

\section{Discussion}

In this study, we documented the persistence of qualitative disturbances of smell and/or taste in $35 \%$ of patients who had COVID-19 acute infection. Compared to age- and sexmatched healthy controls, our patients also showed a significant persistent decrease in olfactory but not taste function. However, patients who reported phantosmia/parosmia and those who did not showed similar reduction in the olfactory function.

Persistent phantosmia has recently been described as a long-term symptom in a number of patients, while data on persistent parosmia are sparse [7]. Persistent parageusia has been reported in about $10 \%$ of patients 60.3 \pm 13.6 days after COVID-19 acute infection while gustatory hallucination has never been described as sequalae of COVID-19 [4]. Therefore, this is the first report of phantogeusia as a persistent symptom of the 2019 novel coronavirus SARS-CoV-2 infection. By contrast, loss/reduction of smell/taste has been already investigated in patients who suffered from COVID-19, with results indicating only a
Fig 1. Sniffin' Sticks Test scores (A) and Taste Strips scores $(\mathbf{B})$ of the 17 patients who had COVID-19 and the 21 healthy controls.
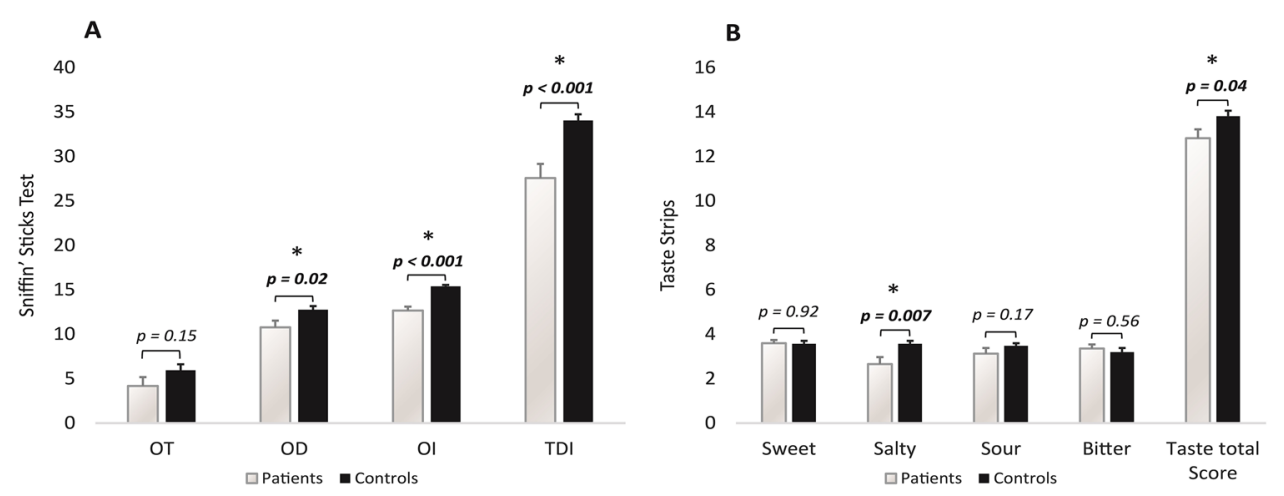
partial improvement of smell/taste disorders 40 days after diagnosis in about one-third of patients [26, 27].

Since phantosmia/parosmia may be associated with olfactory loss [28], we assessed olfactory detection ability with the Sniffin' Sticks Test that evaluates three parameters (i.e., OT, OD, and OI) probably reflect different pathways of activation in the olfactory system. OT is considered to be related to nasal epithelium and individual differences in the nasal cavity, while OD and OI are usually associated to central pathways connecting the orbitofrontal cortex, the piriform cortex, and the amygdala [29]. We found a significant decrease of quantitative smell function in the group of patients who had COVID-19 even though no significant differences in OT, OD, and OI were observed between patients who reported qualitative smell disturbances and those who did not. This does not support quantitative smell impairment as a significant factor contributing to phantos$\mathrm{mia} /$ parosmia in our patients. Even though olfactory loss and phantosmia/parosmia may coexist [28], our finding is nevertheless in line with the observation that qualitative smell disorders may also occur among subjects with normal olfactory function [30-32]. The lack of taste loss (as assessed by Taste Strips test) in our patients with qualitative gustatory disturbances suggests that also parageusia/ phantogeusia may be associated with a normal taste system. Since parageusia/phantosmia seems to be a central phenomenon, we checked whether OD and OI scores (the ones associated to central pathways) were more reduced in the patients who had parageusia/phantosmia associated with quantitative smell disturbances. Probably due to the very low number of study participants, we were not able to find any significant statistical power toward such finding.

The pathophysiology of smell and taste impairment secondary to the 2019 novel coronavirus SARS-CoV-2 infection remains to be elucidated [33]. However, several previous studies proposed pathophysiological hypotheses of olfactory/smell dysfunctions after COVID-19. Anosmia was related to olfactory bulb atrophy on MRI in a patient with COVID-19 [34], and similar findings have been confirmed in other studies [35, 36]. Interestingly, elevated levels of cytokine were found in the olfactory epithelium of COVID-19 patients suggesting that the direct inflammation of the olfactory tract could play a crucial role in the development of sensory loss [37].

Hyposmia may be an early known pre-motor symptom in Parkinson's disease. This raises the possibility of a contribution of COVID-19 in the development of this multifactorial condition [38]. Although few cases of parkinsonism have been described after 2019 novel coronavirus SARS-CoV-2 infection, the causal relationship between COVID-19 and the development of Parkinson's disease is not yet supported by robust clinical/etiopathogenic evidence $[39,40]$.
This study has some limitations. We did not objectively evaluate taste/smell function during the acute phase of the 2019 novel coronavirus SARS-CoV-2. We also did not evaluate other clinical/behavioral long COVID symptoms like fatigue, breathlessness, and muscle and body aches. Therefore, we did not know whether our patients with persistent qualitative smell/taste disturbances could be considered as "Long COVID" patients, according to the definition of the National Institute for Health and Care Excellence [6]. The small sample size and the low associated study power reduced the possibility to assess the prevalence of qualitative smell and taste disorders as well as their association with the olfactory and taste objective impairment. We also could not provide any magnetic resonance imaging data about olfactory-related areas of patients who had anosmia/hyposmia during the acute COVID-19 phase. Nevertheless, our findings shed more light on the possible long-term neurological sequalae of COVID-19. Further research is needed in order to better evaluate the frequency of phantosmia, parosmia, phantogeusia, and parageusia in patients who had COVID19 , and to better characterize their pathophysiology.

Funding Open access funding provided by Universita degli Studi di Cagliari within the CRUI-CARE Agreement.

\section{Declarations}

Conflict of interest The authors declare no competing interests.

Ethical approval None

Consent to participate Participants received an explanatory statement and gave their written informed consent to participate to the study. We also confirm that we have read the Journal's position on issues involved in ethical publication and affirm that this work is consistent with those guidelines.

Open Access This article is licensed under a Creative Commons Attribution 4.0 International License, which permits use, sharing, adaptation, distribution and reproduction in any medium or format, as long as you give appropriate credit to the original author(s) and the source, provide a link to the Creative Commons licence, and indicate if changes were made. The images or other third party material in this article are included in the article's Creative Commons licence, unless indicated otherwise in a credit line to the material. If material is not included in the article's Creative Commons licence and your intended use is not permitted by statutory regulation or exceeds the permitted use, you will need to obtain permission directly from the copyright holder. To view a copy of this licence, visit http://creativecommons.org/licenses/by/4.0/.

\section{References}

1. Vaira LA, Hopkins C, Salzano G, Petrocelli M, Melis A, Cucurullo M, Ferrari M, Gagliardini L, Pipolo C, Deiana G, Fiore V, De Vito A, Turra N, Canu S, Maglio A, Serra A, Bussu F, 
Madeddu G, Babudieri S et al (2020) Olfactory and gustatory function impairment in COVID-19 patients: Italian objective multicenter-study. Head Neck 42:1560-1569. https://doi.org/10. 1002/hed.26269

2. Lechien JR, Chiesa-Estomba CM, Hans S, Barillari MR, Jouffe L, Saussez S (2020) Loss of smell and taste in 2013 European patients with mild to moderate COVID-19. Ann Intern Med 173:672-675. https://doi.org/10.7326/M20-2428

3. Hummel T, Whitcroft KL, Andrews P, Altundag A, Cinghi C, Costanzo RM, Damm M, Frasnelli J, Gudziol H, Gupta N, Haehne A, Holbrook E, Hong SC, Hornung D, Huttenbrink KB, Kamel R, Kobayashi M, Konstantinidis I, Landis BN et al Position paper on olfactory dysfunction. Rhinol J 54(2017):1-30. https://doi.org/10. 4193/Rhino16.248

4. Carfì A, Bernabei R, Landi F (2020) Persistent symptoms in patients after acute COVID-19. JAMA 324:603. https://doi.org/ 10.1001/jama.2020.12603

5. Lechien JR, Chiesa-Estomba CM, Beckers E, Mustin V, Ducarme M, Journe F, Marchant A, Jouffe L, Barillari MR, Cammaroto G, Circiu MP, Hans S, Saussez S (2021) Prevalence and 6-month recovery of olfactory dysfunction: a multicentre study of 1363 COVID-19 patients. J Intern Med:1-11. https://doi.org/10.1111/ joim. 13209

6. National Institute for Health and Care Excellence, R.C. of G. Practitioners, H.I. Scotland (2020) COVID-19 rapid guideline : managing the long-term effects of COVID-19, NICE Guidel. 1-35.

7. İşlek A, Balcı MK (2021) Phantosmia with COVID-19 related olfactory dysfunction: report of nine case. Indian J Otolaryngol Head Neck Surg. https://doi.org/10.1007/s12070-021-02505-z

8. Muroni A, Murru MR, Sechi M, Ercoli T, Marrosu F, Bentivoglio AR, Petracca M, Maria Scaglione CL, Soliveri P, Cocco E, Pedron M, Murgia M, Deriu M, Cuccu S, Ulgheri L, Zuccato C, Defazio G (2020) Prevalence of Huntington's disease in Southern Sardinia, Italy. Park Relat Disord 80:54-57. https://doi.org/10.1016/j.parkr eldis.2020.09.011

9. Ercoli T, Lutzoni L, Orofino G, Muroni A, Defazio G (2021) Functional neurological disorder after COVID-19 vaccination. Neurol Sci:2-3. https://doi.org/10.1007/s10072-021-05504-8

10. World Health Organization, Clinical management of COVID19: interim guidance, 27 May 2020, World Health Organization, Geneva PP - Geneva, n.d. https://apps.who.int/iris/handle/10665/ 332196

11. Howell J, Costanzo RM, Reiter ER (2018) Head trauma and olfactory function. World J Otorhinolaryngol - Head Neck Surg 4:39-45. https://doi.org/10.1016/j.wjorl.2018.02.001

12. Defazio G, Fabbrini G, Erro R, Albanese A, Barone P, Zibetti M, Esposito M, Pellicciari R, Avanzino L, Bono F, Eleopra R, Bertolasi L, Altavista MC, Cotelli MS, Ceravolo R, Scaglione C, Bentivoglio AR, Cossu G, Moja MC et al (2020) Does acute peripheral trauma contribute to idiopathic adult-onset dystonia? Parkinsonism Relat Disord 71:40-43. https://doi.org/10.1016/j. parkreldis.2020.01.002

13. Pellegrino R, Farruggia MC, Small DM, Veldhuizen MG (2021) Post-traumatic olfactory loss and brain response beyond olfactory cortex. Sci Rep 11:4043. https://doi.org/10.1038/ s41598-021-83621-2

14. Tinazzi M, Geroin C, Erro R, Marcuzzo E, Cuoco S, Ceravolo R, Mazzucchi S, Pilotto A, Padovani A, Romito LM, Eleopra R, Zappia M, Nicoletti A, Dallocchio C, Arbasino C, Bono F, Pascarella A, Demartini B, Gambini O, Modugno N, Olivola E, Bonanni L, Antelmi E, Zanolin E, Albanese A, Ferrazzano G, Micco R, Lopiano L, Calandra-Buonaura G, Petracca M, Esposito M, Pisani A, Manganotti P, Stocchi F, Coletti Moja M, Antonini A, Ercoli T, Morgante F (2021) Functional motor disorders associated with other neurological diseases: beyond the boundaries of "organic" neurology. Eur J Neurol 1-7. https://doi.org/10.1111/ene.14674.
15. Tinazzi M, Geroin C, Marcuzzo E, Cuoco S, Ceravolo R, Mazzucchi S, Pilotto A, Padovani A, Romito LM, Eleopra R, Zappia M, Nicoletti A, Dallocchio C, Arbasino C, Bono F, Magro G, Demartini B, Gambini O, Modugno N et al (2021) Functional motor phenotypes: to lump or to split? J Neurol. https://doi.org/ 10.1007/s00415-021-10583-w

16. Herr T, Hummel T, Vollmer M, Willert C, Veit B, Gamain J, Fleischmann R, Lehnert B, Mueller JU, Stenner A, Kronenbuerger M (2020) Smell and taste in cervical dystonia. J Neural Transm 127:347-354. https://doi.org/10.1007/s00702-020-02156-4

17. Doty RL (2012) Olfaction in Parkinson's disease and related disorders. Neurobiol Dis. https://doi.org/10.1016/j.nbd.2011.10.026

18. Tinazzi M, Erro R, Mascia MM, Esposito M, Ercoli T, Ferrazzano G, Di Biasio F, Pellicciari R, Eleopra R, Bono F, Bertolasi L, Barone P, Scaglione CLM, Pisani A, Altavista MC, Cotelli MS, Ceravolo R, Cossu G, Zibetti M et al (2020) Demographic and clinical determinants of neck pain in idiopathic cervical dystonia. J Neural Transm 127:1435-1439. https://doi.org/10. 1007/s00702-020-02245-4

19. Liu G, Zong G, Doty RL, Sun Q (2016) Prevalence and risk factors of taste and smell impairment in a nationwide representative sample of the US population: a cross-sectional study. BMJ Open 6:e013246. https://doi.org/10.1136/bmjopen-2016-013246

20. Solla P, Masala C, Liscia A, Piras R, Ercoli T, Fadda L, Hummel T, Haenher A, Defazio G (2019) Sex-related differences in olfactory function and evaluation of possible confounding factors among patients with Parkinson's disease. J Neurol. https:// doi.org/10.1007/s00415-019-09551-2

21. Landis BN, Welge-Luessen A, Brämerson A, Bende M, Mueller CA, Nordin S, Hummel T (2009) "Taste strips"-a rapid, lateralized, gustatory bedside identification test based on impregnated filter papers. J Neurol 256:242-248. https://doi.org/10. 1007/s00415-009-0088-y

22. Solla P, Masala C, Pinna I, Ercoli T, Loy F, Orofino G, Fadda L, Defazio G (2021) Frequency and determinants of olfactory hallucinations in Parkinson's disease patients. Brain Sci 11:841. https://doi.org/10.3390/brainsci11070841

23. Defazio G, Ercoli T, Erro R, Pellicciari R, Mascia MM, Fabbrini G, Albanese A, Lalli S, Eleopra R, Barone P, Marchese R, Ceravolo R, Scaglione C, Liguori R, Esposito M, Bentivoglio AR, Bertolasi L, Altavista MC, Bono F et al (2020) Idiopathic non-task-specific upper limb dystonia, a neglected form of dystonia. Mov Disord 35:2038-2045. https://doi.org/10.1002/mds. 28199

24. Ercoli T, Defazio G, Muroni A (2019) Cerebellar syndrome associated with thyroid disorders. Cerebellum 18:932-940. https://doi. org/10.1007/s12311-019-01059-9

25. Dagostino S, Ercoli T, Gigante AF, Pellicciari R, Fadda L, Defazio G (2019) Sensory trick in upper limb dystonia. Park Relat Disord. https://doi.org/10.1016/j.parkreldis.2019.01.006

26. Mastrangelo A, Bonato M, Cinque P (2021) Smell and taste disorders in COVID-19: from pathogenesis to clinical features and outcomes. Neurosci Lett 748:135694. https://doi.org/10.1016/j. neulet.2021.135694

27. Nalbandian A, Sehgal K, Gupta A, Madhavan MV, McGroder C, Stevens JS, Cook JR, Nordvig AS, Shalev D, Sehrawat TS, Ahluwalia N, Bikdeli B, Dietz D, Der-Nigoghossian C, Liyanage-Don N, Rosner GF, Bernstein EJ, Mohan S, Beckley AA et al (2021) Post-acute COVID-19 syndrome. Nat Med 27:601-615. https:// doi.org/10.1038/s41591-021-01283-Z

28. Bonfils P, Avan P, Faulcon P, Malinvaud D (2005) Distorted odorant perception. Arch Otolaryngol Neck Surg 131:107. https://doi. org/10.1001/archotol.131.2.107

29. Masala C, Käehling C, Fall F, Hummel T (2019) Correlation between olfactory function, trigeminal sensitivity, and nasal 
anatomy in healthy subjects. Eur Arch Oto-Rhino-Laryngol 276:1649-1654. https://doi.org/10.1007/s00405-019-05367-y

30. Douek E (1970) Some abnormalities of smell. J Laryngol Otol 84:1185-1191. https://doi.org/10.1017/S0022215100072935

31. RB GJG, Catalanotto FA (1986) Clinical characteristics of patients with taste and smell disorders. In: Meiselman HL, Rivlin RS (eds) Ed. Clin. Meas. OfTaste Smell. Macmillan, NewYork, pp 451-466

32. Ciurleo R, De Salvo S, Bonanno L, Marino S, Bramanti P, Caminiti F (2020) Parosmia and neurological disorders: a neglected association. Front Neurol 11:1-7. https://doi.org/10.3389/fneur. 2020.543275

33. Ren AL, Digby RJ, Needham EJ (2021) Neurological update: COVID-19. J Neurol. https://doi.org/10.1007/ s00415-021-10581-y

34. Chiu A, Fischbein N, Wintermark M, Zaharchuk G, Yun PT, Zeineh M (2021) COVID-19-induced anosmia associated with olfactory bulb atrophy. Neuroradiology 63:147-148. https://doi. org/10.1007/s00234-020-02554-1

35. Kandemirli SG, Altundag A, Yildirim D, Tekcan Sanli DE, Saatci O (2021) Olfactory bulb MRI and paranasal sinus CT findings in persistent COVID-19 anosmia. Acad Radiol 28:28-35. https://doi. org/10.1016/j.acra.2020.10.006

36. Hajjij A, Benslima N, Aasfara J, Bensouda H, Mahi M, Benariba F (2021) MRI of the olfactory tract in a case of post-COVID-19 persistent anosmia. Integr J Med Sci 8:1-3. https://doi.org/10. 15342/ijms.2021.406
37. Torabi A, Mohammadbagheri E, Akbari Dilmaghani N, Bayat AH, Fathi M, Vakili K, Alizadeh R, Rezaeimirghaed O, Hajiesmaeili M, Ramezani M, Simani L, Aliaghaei A (2020) Proinflammatory cytokines in the olfactory mucosa result in COVID-19 induced anosmia. ACS Chem Neurosci 11:1909-1913. https:// doi.org/10.1021/acschemneuro.0c00249

38. Belvisi D, Pellicciari R, Fabbrini A, Costanzo M, Pietracupa S, De Lucia M, Modugno N, Magrinelli F, Dallocchio C, Ercoli T, Terravecchia C, Nicoletti A, Solla P, Fabbrini G, Tinazzi M, Berardelli A, Defazio G (2020) Risk factors of Parkinson disease: simultaneous assessment, interactions, and etiologic subtypes. Neurology 95:e2500-e2508. https://doi.org/10.1212/WNL.00000 00000010813

39. Merello M, Bhatia KP, Obeso JA (2021) SARS-CoV-2 and the risk of Parkinson's disease: facts and fantasy. Lancet Neurol 20:94-95. https://doi.org/10.1016/S1474-4422(20)30442-7

40. Makhoul K, Jankovic J (2021) Parkinson's disease after COVID19. J Neurol Sci 422:117331. https://doi.org/10.1016/j.jns.2021. 117331

Publisher's note Springer Nature remains neutral with regard to jurisdictional claims in published maps and institutional affiliations. 